\title{
Epidemiology of Bladder Malignancies in the Patients Treated by Trans Urethral Resection in Kurdistan Province in 2012-2017
}

Heshmatollah SoofiMajidpour ${ }^{1}$, Arman Karami Khaman², Mozhdeh Amiri ${ }^{3}$, Bushra Zareie ${ }^{4}$, Hooshmand Sofimajidpour ${ }^{5}$, Mohammad Aziz Rasouli ${ }^{6}$

1. Professor, Department of Urology, Faculty of Medicine, Kurdistan University of Medical Sciences, Sanandaj, Iran ORCID ID: 0000-0002-9669-2376

2. Medical Student, Student Research Committee, Kurdistan University of Medical Sciences, Sanandaj, Iran ORCID ID: 0000$0002-4432-2436$

3. M.Sc Epidemiology, Student Research Committee, Kurdistan University of Medical Sciences, Sanandaj, Iran ORCID ID: 0000-0001-9256-3115

4. PhD Student of Epidemiology, Department of Epidemiology, School of Public Health, Hamadan University of Medical Science, Hamadan, Iran ORCID ID: 0000-0002-8307-4835

5.Assistant Professor, Department of Urology, Faculty of Medicine, Kurdistan University of Medical Sciences, Sanandaj, Iran ORCID ID: 0000-0001-6829-0823

6. M.Sc of Epidemiology, Clinical Research and Development Unit, Kowsar Hospital, Kurdistan University of Medical Sciences, Sanandaj, Iran (Correspondence Author), Tel: +98-8733611250, E-mail: Rasouli1010@gmail.com, ORCID ID: 0000-0003-3359-774X

\section{ABSTRACT}

Background and Aim: Bladder cancer is the ninth most common cancer in the world. Also, it is the fourth most common cancer in men in Iran and the second most common genitourinary cancer after prostate cancer. This study deals with epidemiology of bladder malignancy in the patients treated by transurethral resection in Tohid Hospital in Sanandaj.

Materials and Methods: In this cross-sectional study, data were extracted from321 medical records of the patients with bladder malignancy treated by transurethral resection from 2012 to 2017. Data included age, gender, place of residence, occupation, smoking history, histopathology results, disease stage and type of treatment. Frequency and percentage of every variable was calculated. Stata software Ver. 14 was used for data analysis.

Results: The results of this study showed that mean \pm standard deviation of age of the subjects was $65.6 \pm 14$ years. $264(82.2 \%)$ patients were men and $247(76.9 \%)$ lived in Sanandaj city. 172 patients $(53.6 \%)$ had history of smoking and 20 patients $(6.2 \%)$ had family history of bladder cancer. Histopathology reports of most patients were indicative of transitional cell carcinoma. 210 patients $(65.4 \%)$ were at stage 1 and 8 patients $(2.5 \%)$ at stage 4 of the disease. Treatment methods were TURBT in 207 patients $(64.5 \%)$ and TURBT and BCG into the bladder in 74 patients (23\%). Age, gender and disease stage showed no significant statistical association with one another $(\mathrm{P}>0.05)$.

Conclusion: The incidence of bladder cancer is on the rise, although this increase may be due to improved cancer registration system, as well as use of new diagnostic methods and increased patients' awareness, but change in lifestyle, adverse effects of job on health and other risk factors can lead to increased risk of bladder cancer. Therefore, planning for identification of the causes of this cancer can be helpful in prevention of this cancer.

Keywords: Bladder malignancy, Transurethral resection, Urinary tract, Kurdistan

Received: July 22, 2020 Accepted: Dec 20, 2020

\footnotetext{
How to cite the article: Heshmatollah SoofiMajidpour, Arman Karami Khaman, Mozhdeh Amiri, Bushra Zareie, Hooshmand Sofimajidpour, Mohammad Aziz Rasouli. Epidemiology of bladder malignancies in

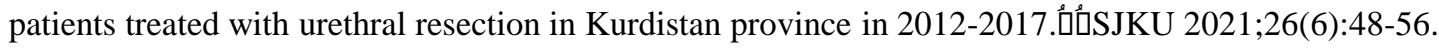

Copyright $₫ 2018$ the Author (s). Published by Kurdistan University of Medical Sciences. This is an open access article distributed under the terms of the Creative Commons Attribution-Non Commercial License 4.0 (CCBYNC), where it is permissible to download, share, remix, transform, and buildup the work provided it is properly cited. The work cannot be used commercially without permission from the journal
} 


\section{إيدميولوزى بدخيمى هاى مثانه در بيماران تحت درمان با برداشت از طريق مجراى

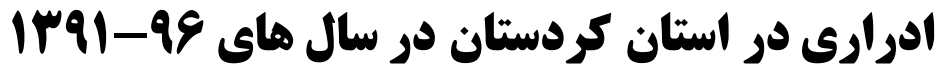

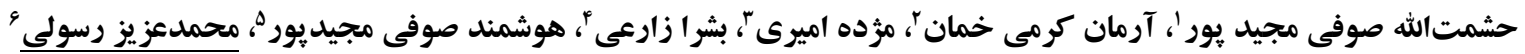

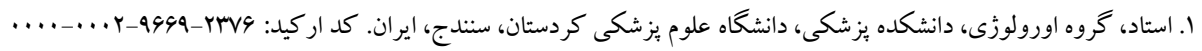

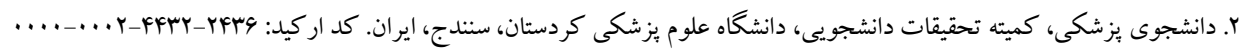

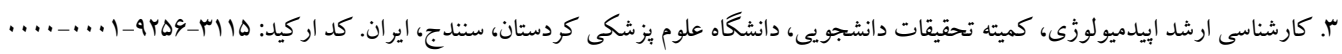

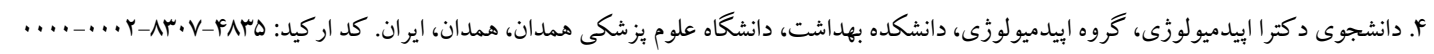

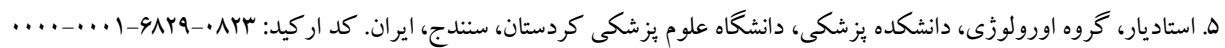

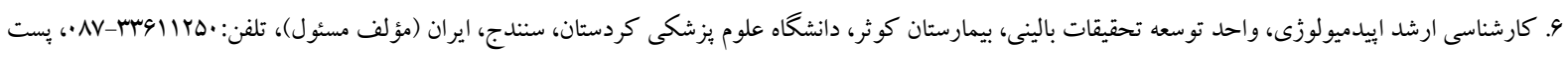

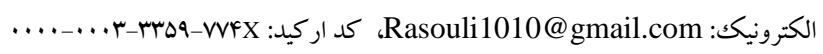

جكکبه

زمينه و هدف: سرطان مثانه نهمين سرطان شايع در دنيا و جهارمين سرطان شايع در مردان در ايران و دومين سرطان دستكاه

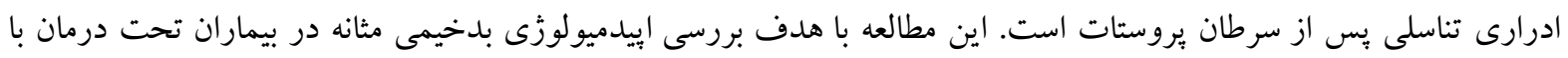

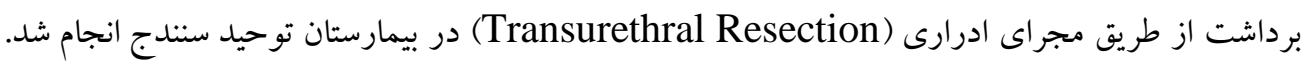

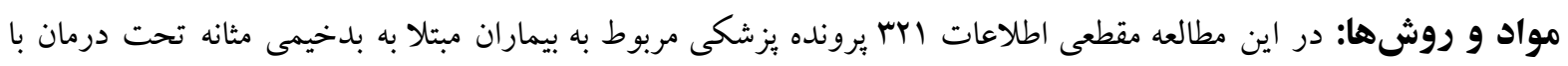

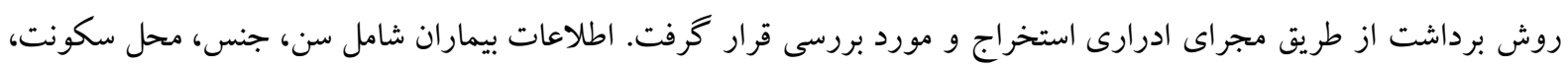

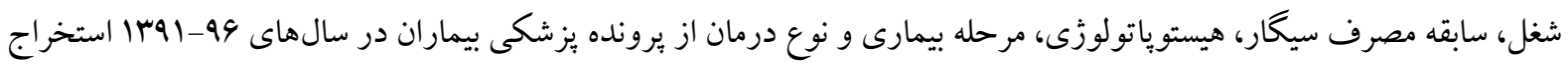

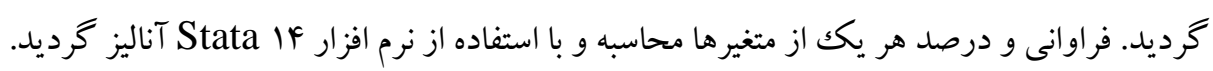

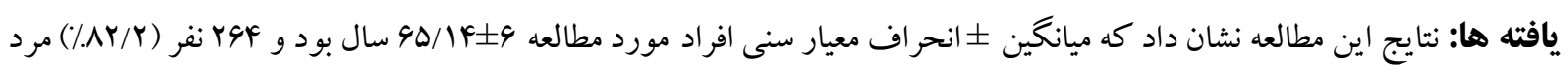

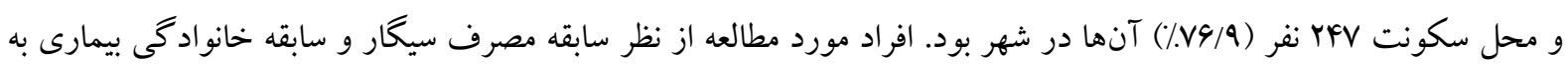

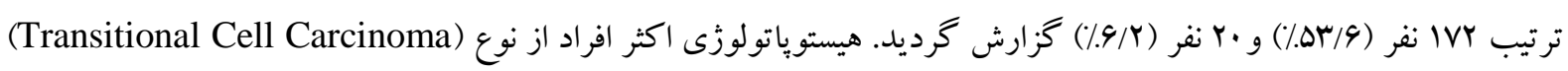

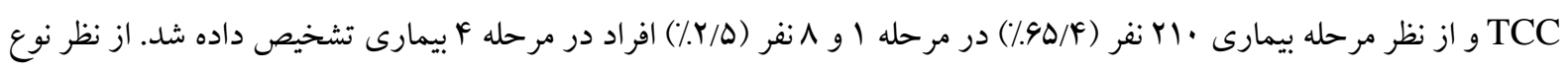

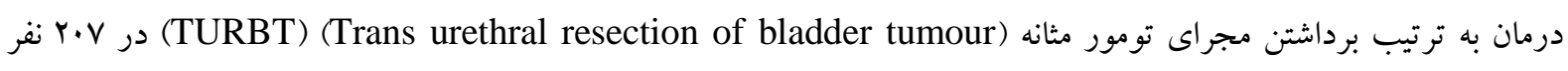

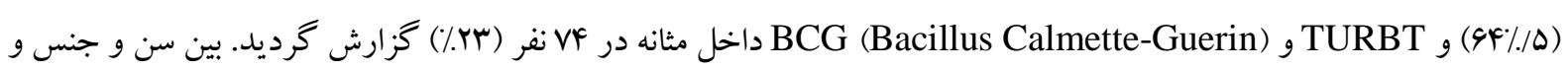

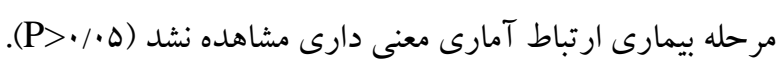

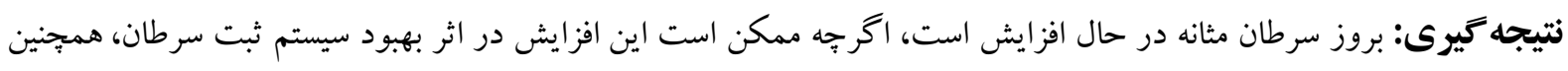

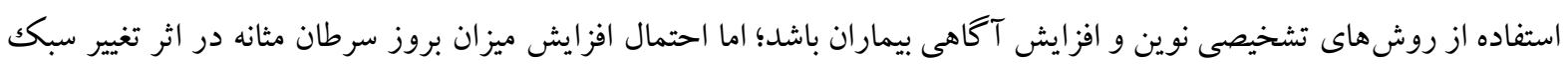

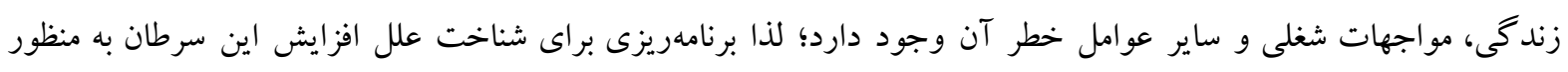

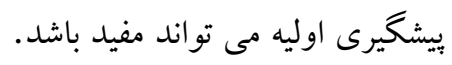

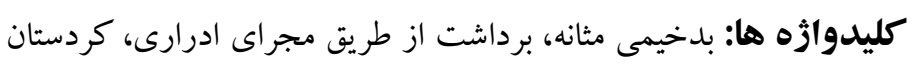

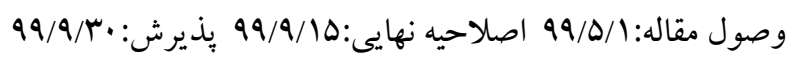


متوسط هنگام تشخيص در مردان 99 سال و در زنان الVال سال

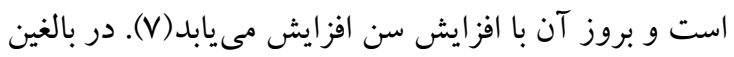

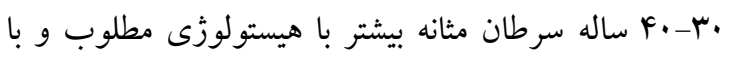

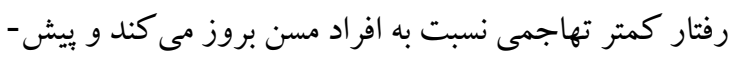

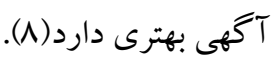

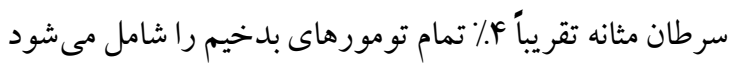
و بروز آن در حال افزايش است و حداكثر بروز آن در دهه هفتم است و فقط 1\% بيماران سن كمتر از هـ سال دارند(9).

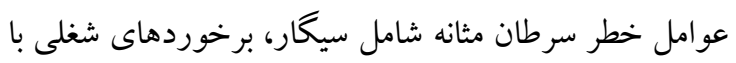
كارسينوزنها، تحريككهاى مزمن استعدادهاى زُنتيكى بوده

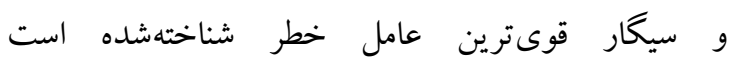
بهطورى كه F-Y برابر خطر سرطان مثانه را افزايش مى دهد (9).

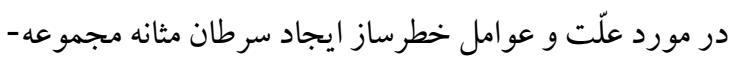

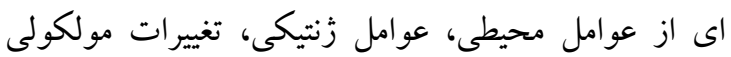

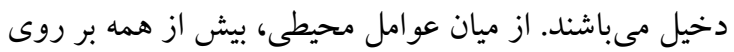

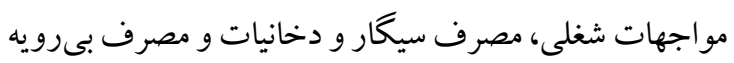

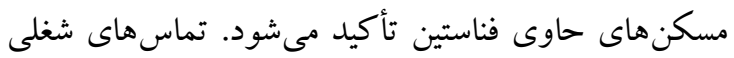

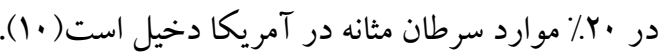

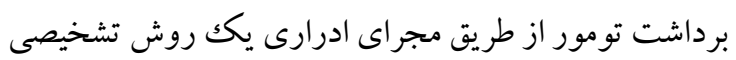
و درمانى در سرطان مثانه است. از جنبه تشخيصى جهت تعريين

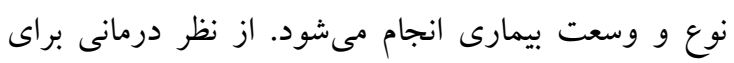
درمان تمامى تومورهاى ماكروسكوييك غير تهاجمى مثانه

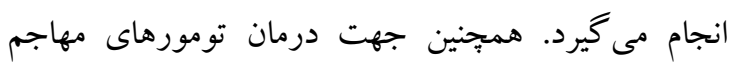

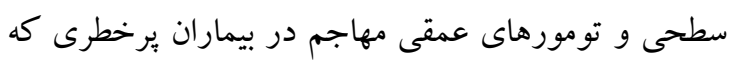

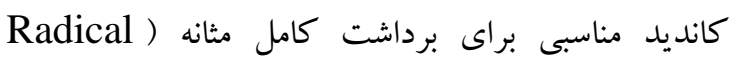

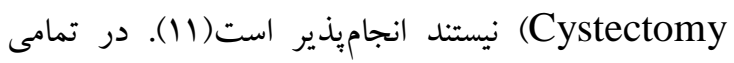
بيمارانى كه با علائم بالينى مشكو كك به سرطان مثانه تحت

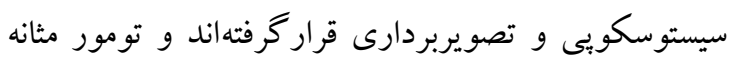
تشخيص داده شده است بايد تحت برداشت از طريق مجراى

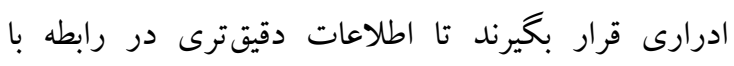

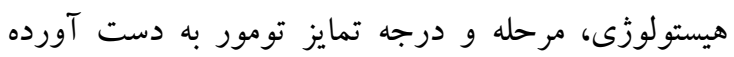

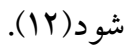

\section{مقدمه} سرطان مثانه ضايعه بدخيمى است كه از سلول هاى بافت مثانه

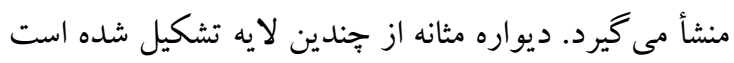

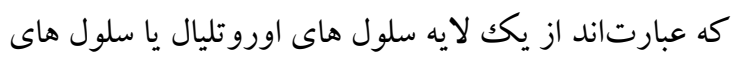

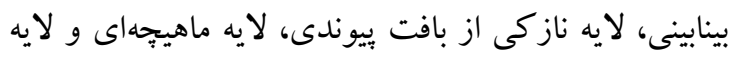

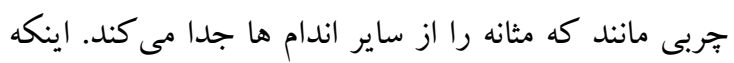

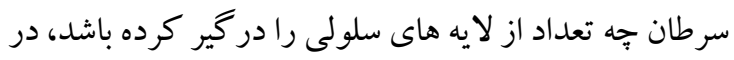
تعيين ييش آكهى اين بيمارى و انتخاب روش درمانى كمكك

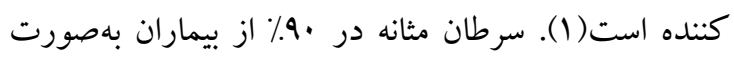

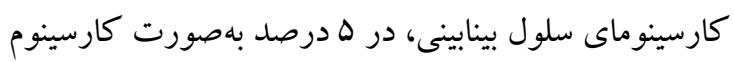
سلول هاى يوششى و rا٪ بهصورت كارسينوماى سلول هاى

$$
\text { ترشحى رخ مى دهد (r, (1,). }
$$

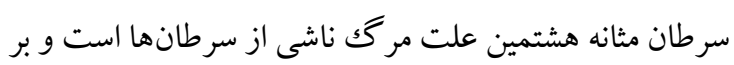
اساس آمار موجود جهارمين سرطان شايع و نهمين علت

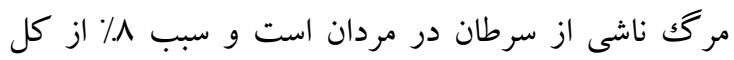
تومورها و سه درصد مر گكهاى ناشى از سرطان در مردان

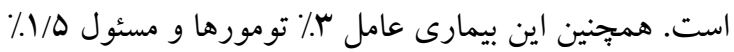

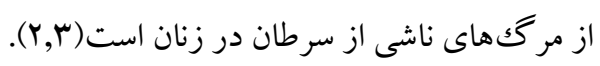

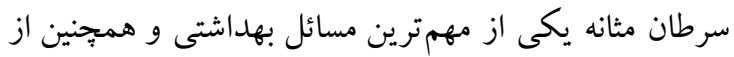

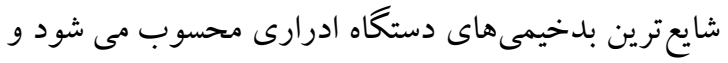
دومين تومور تناسلى است كه باعث ابتلا و مركى و مير در

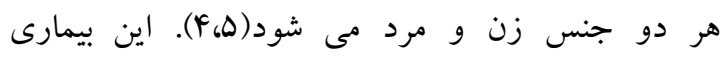

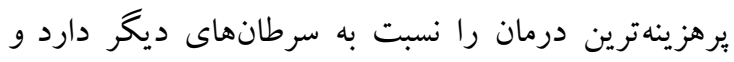
إيدميولوزى سرطان مثانه نشان مى دهد كه سرطان مثانه

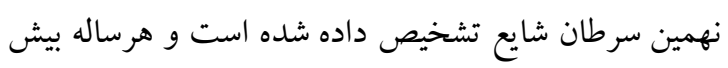

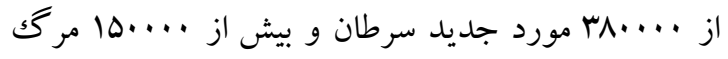

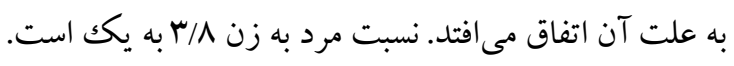
سرطان مثانه در ايران، سومين سرطان شايع در مردان است.

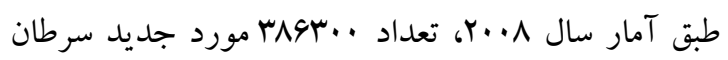

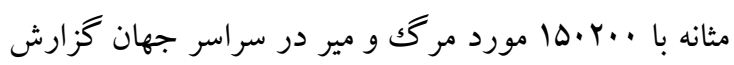

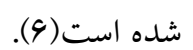

سرطان مثانه در هر سنى حتى در بجِهها ممكن است ايجاد

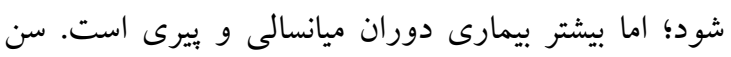


BCG

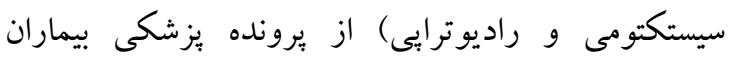

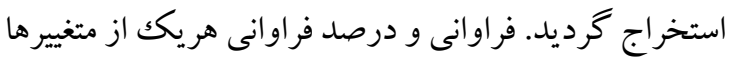
محاسبه و ارتباط سن و جنس با مر حله بيمارى بر آورد گرديد.

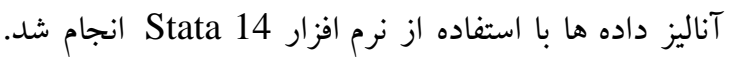
سطح معنى دارى در اين مطالعه ه./.> P Pر نظر خرفته شد.

يافته ها

نتايج اين مطالعه نشان داد كه ميانخين 土ـانحر اف معيار سنى

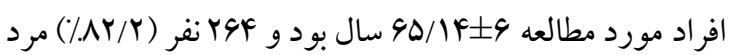
و محل سكونت YFV نفر (V9/9/) آنها در شهر بود. از نظر

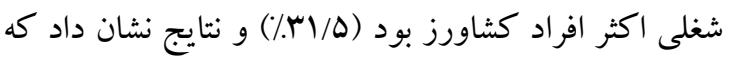

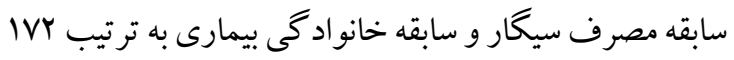

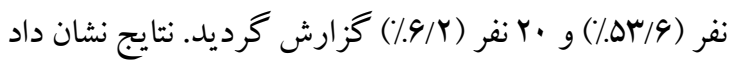
كه هيستوياتولوزى اكثر افراد از نوع Transitional Cell Carcinoma و از نظر فراوانى افراد از نظر مرحله بيمارى نتايج نشان داد كه

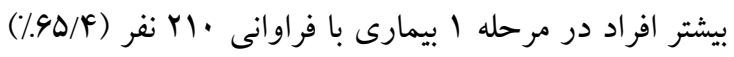

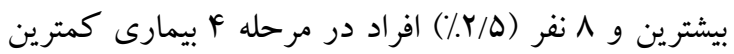
فراوانى تشخيص داده شدند. از نظر نوع درمان به ترتيب

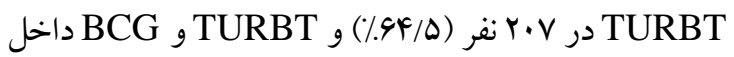

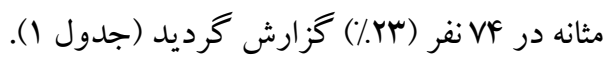

با توجه به اهميت بالينى اين بيمارى و اين واقعيت كه

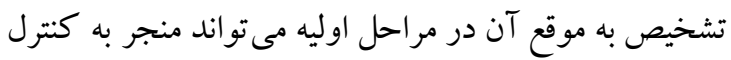
بيمارى و افزايش بقا گردد؛ بنابراين شناخت اييدميولوزيكك اين ضايعه مىتواند در تدوين برنامهاى بهداشتى، ييشخيرى

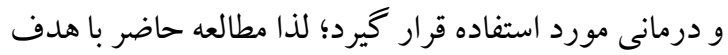
بررسى إيدميولوزى بدخيمى هاى مثانه در بيماران تحت درمان با برداشت از طريق مجراى ادرارى در بيمارستان

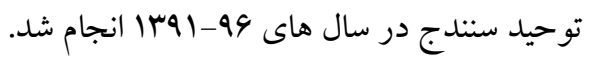

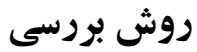

در اين مطالعه مقطعى اطلاعات البr بِرونده بز شكى مربوط

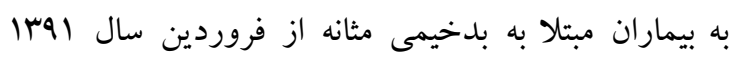
لغايت اسفند سال وهrا كه در بيمارستان توحيد سنندج تحت درمان با روش برداشت از طريق مجراى ادرارى

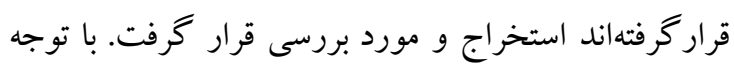
به اينكه تمام جراحىهاى برداشت از طريق مجراى ادرارى

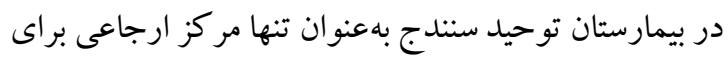
اين بروسيجر در استان كردستان انجام و بهصورت سرشمارى

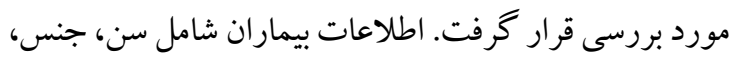

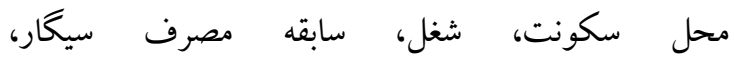

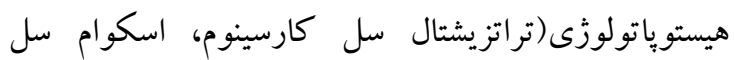
كارسينوما، آدنو كارسينوما)، مرحله بيمارى(مرحله ل، ك، با و F) و نوع درمان(برداشتن مجراى تومور مثانه (TURBT)،

جدول ا. توزيع فراوانى بدخيمى هاى مثانه در بيماران تحت درمان با برداشت از طريق مجراى ادرارى

\begin{tabular}{|c|c|c|c|}
\hline درصد & فراوانى & متغير & \\
\hline$\Lambda Y / Y$ & rap & مرد & جنسيت \\
\hline $\mathrm{IV} / \mathrm{A}$ & $\Delta V$ & زن & \\
\hline$V 9 / q$ & YFV & شهر & محل سكونت \\
\hline$r r / l$ & $V F$ & روستا & \\
\hline$M / \Delta$ & 1.1 & كشاورز & شغل \\
\hline $19 / 1$ & $\Delta F$ & كارمند & \\
\hline $19 / 0$ & r & كارFر & \\
\hline $14 / 9$ & PV & خانه دار & \\
\hline$r \cdot 19$ & 99 & ساير & \\
\hline
\end{tabular}




\begin{tabular}{|c|c|c|}
\hline$\Delta r / 9$ & IVT & سابقه مصرف سيكار بله \\
\hline$k 9 / 4$ & $1 F q$ & 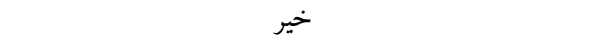 \\
\hline $9 / 4$ & $r$ r. & 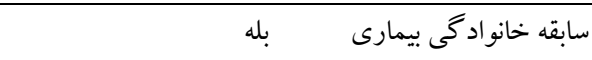 \\
\hline $9 \pi / \Lambda$ & $r \cdot 1$ & 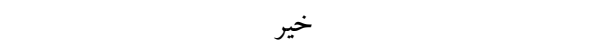 \\
\hline $90 / F$ & r. & مرحله (Stage) بيمارى مرحله I \\
\hline$r m / l$ & VF & 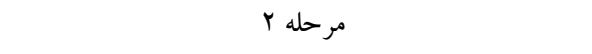 \\
\hline 9 & rq & 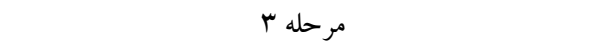 \\
\hline$r / \Delta$ & $\wedge$ & مرحله F \\
\hline $9 F / V$ & $r \cdot F$ & هيستوياتولوزى Transitional Cell Carcinoma \\
\hline$r / l$ & 1. & آ آدنو كارسينوما \\
\hline$r / Y$ & $\checkmark$ & اسكوام سل كارسينوما \\
\hline $94 / 0$ & $r \cdot V$ & TURBT \\
\hline rr & VF & PURBT و TUCG داخل مثانه \\
\hline$V / \Delta$ & YF & شيمى درمانى سيستميك \\
\hline$r / l$ & ir & 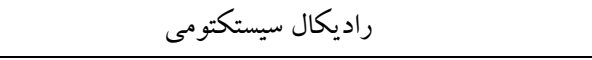 \\
\hline 1. & rr & شيمى درمانى و راديوترايى \\
\hline $1 / 9$ & 9 & نامشخص \\
\hline
\end{tabular}

بيماران ارتباط آمارى معنىدارى وجود ندارد (Pه (P=/9ه). همجينين سن بيماران بر اساس مرحله بيمارى، تفاوت آمارى

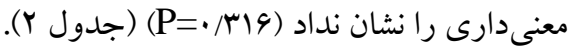

بيشترين فراوانى مرحله | بيمارى در مردان سل المورد (

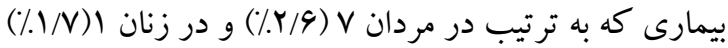
بود. نتايج نشان داد كه بين جنسيت و مرحله بيمارى در

جدول r. ارتباط سن و جنس با مرحله تومور بدخيمى مثانه در بيماران تحت درمان با برداشت از طريق مجر اى ادرارى

\begin{tabular}{|c|c|c|c|c|c|c|}
\hline P-value & مرحله P & مرحله r & مرحله r & مرحله 1 & \multicolumn{2}{|c|}{ متغيير } \\
\hline.$/ 9 \Delta \Delta$ & $V(Y / 9)$ & $r \mu(\Lambda / V)$ & $91(Y \mu / Y)$ & $\ln (9 \Delta / \Delta)$ & مرد & جنسيت \\
\hline & $1(1 / V)$ & $9(1 \cdot 19)$ & $\mathbb{I}(Y Y / A)$ & $r V(G F / q)$ & زن & \\
\hline . & $q r / l r \pm r / r$ & $v \cdot / r \pm F / \Lambda$ & $\mid r \pm 9 \Delta / r$ & $9 \Delta / I F \pm Y / F$ & : ميانكين) & ل (انحر اف \\
\hline
\end{tabular}

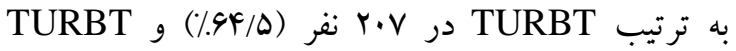

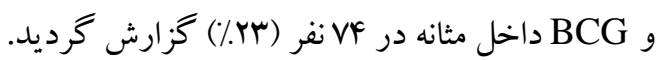
نتايج اين مطالعه نشان داد كه ميانگين سنى افراد مورد مطالعه در مطالعهاى كه با هدف بررسى وضعيت تشخيصى و

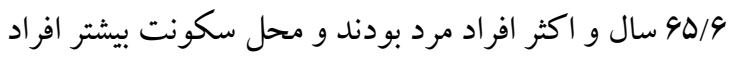

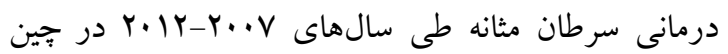
در شهر بود. هيستوياتولوزى اكثر افراد از نونع

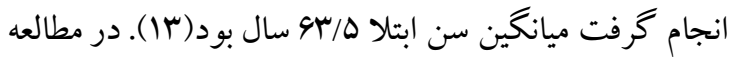
Transitional Cell Carcinoma Pashos و همكاران كه إيدميولوزى تشخيص و مديريت

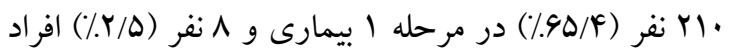

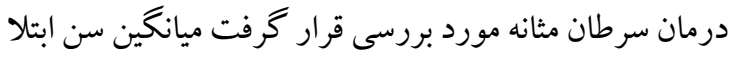
در مر حله fا بيمارى تشخيص داده شده اند. از نظر نوع درمان هبلم علدى دانشكاه علوه بِزشكى كردستان / دوه بيست و شش / آذر و دى م.ع|| 
آن در كهخيلويه و بوير احمد گزارش شده است كه نسبت

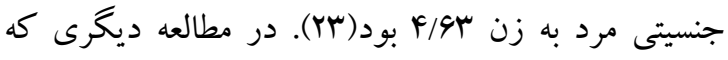
توسط صوفى مجيد يور و همكاران در استان كردستان انجام شد، در فاصله سالهاى سرطان مثانه 194 مورد كزارش شد كه از اين تعداد 19


حالى است كه بر اساس مطالعات انجام شده در ايالات متحده نسبت مرد به زن حدود Y/V به ا است(YF) در حالى كه بر اساس نتايج مطالعه حاضر و ساير مطالعات داخلى اين نسبت حدود F/9 به ا است و اين مسئله نشان دهنده ميزان بروز بالاى سرطان مثانه در مردان استان كردستان است. بروز

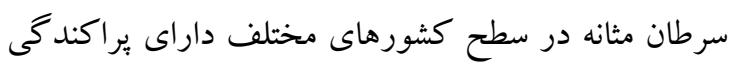
استانى زيادى است و اين مسئله نشان مى دهد كه ميزان بروز اين سرطان در مناطق مختلف تابعى از فرهنگ و آداب و رسوم آن منطقه مى باشد. در جهان مردان f تا ها برابر بيشتر از زنان به سرطان مثانه مبتلا مى شوند كه احتمالاً به خاطر تماس هاى شغلى و تماس بيشتر با دود سيخار درآن

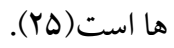
در مطالعه حاضر، V9/9٪ افراد مورد مطالعه ساكن شهر و

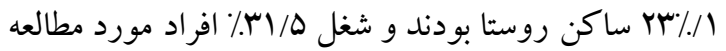
كشاورزى بود. در مطالعه Ejaz و همكاران، ميزان شيوع بيمارى در افراد ساكن روستا نسبت به ساكن شهر ب به .1 بوده است. از طرف ديخر عود بيمارى در كشاورزان تقريباً r برابر ساير مشاغل گزارش شده است(Y9). در مطالعه صوفى مجيديور و همكاران كه در استان كردستان انجام شده

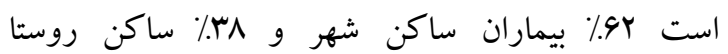
بودند(19). به نظر مىرسد كه اين روند افزايش سكونت بيماران در شهر در مقايسه با مطالعه قبلى در استان كردستان در نتيجه افزايش جمعيت و افزايش مهاجرت از روستا به

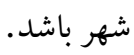
در مطالعه حاضر \%/4\% افراد داراى سابقه خانوادگى ابتلا به سرطان مثانه گزارش شد و 19/ه.\% سابقه مصرف سيكار را ذكر كردند. مهمترين عوامل خطرى كه تاكنون براى
در بيماران مورد بررسى 90/ه سال گزارش گرديد(9). در يكك مطالعه مرورى كه با هدف بررسى اييدميولوزيكك

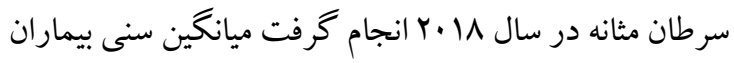
99/V سال بود (1F) و همجنين در مطالعه Cheng و همكاران

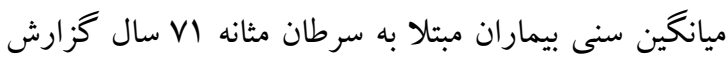

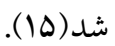

ميزان بروز سرطان مثانه با افزايش سن بيشتر مىشود و بيشترين ميزان بروز در گروه سنى بالاى •^ سال مشاهده شده است، در مطالعه انجام شده در كاليفرنيا سن هN سال بالاترين بروز را داشته است(1) و نتايج مطالعه در هندوستان نشان داد كه افزايش سن بروز سرطان مثانه نيز افزايش مىيابد(IV)كه اين مسئله در مطالعات اييدميولوزيكك ايران نيز تائيد شده است. ميانخين سنى به إنه دست آمده از مطالعه شافى و همكاران در سال |qها در شهرستان بابل V9/9 سال(1) و در مطالعه صوفى مجيديور

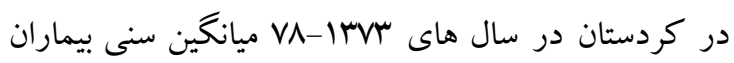

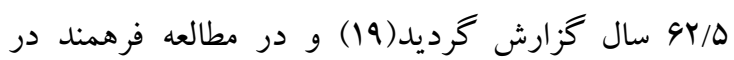
استان فارس ميانكين سنى \& زاده در مازندران نيز گروه سنى .4 تا V9 سال به عنوان يرخطرترين گروه سنى از نظر ابتلا به سرطان مثانه اعلام شده است (Y) (Y) (1) نتايج مطالعه حاضر نشان داد كه ب/ / افراد مورد مطالعه مرد و نسبت مردان به زنان در مطالعه حاضر F/9 به ا بود. در مطالعه رفيعى منش و همكاران كه در فاصله سالهاى r. r.

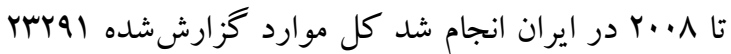
مورد بود كه IV/V٪ موارد زن و س/N/\% موارد مرد بودند و نسبت جنس مرد به زن D, F, به | زن بود(YY) كه با مطالعه حاضر همخوانى دارد. در مطالعه كوهى و همكاران يافتها نشان داد كه بررسى دادههاى نظام ثبت سرطان در ايران در

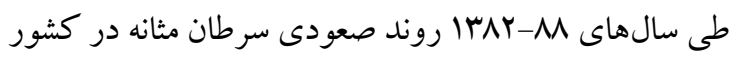
را نشان مىدهد. در كشور بيشترين ميزان بروز در مردان مربوط به تهران و كمترين آن مربوط به خراسان جنوبى و براى زنان بيشترين ميزان بروز در خراسان جنوبى و كمترين 
نتايج مطالعه حاضر نشان داد كه 9/4\% افراد مورد مطالعه

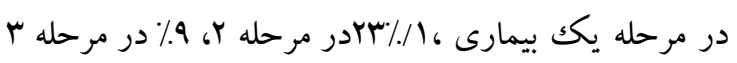

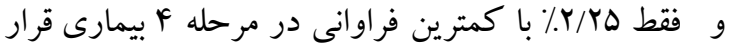
داشتند. در مطالعه قبلى كه توسط صوفى مجيد يور و و

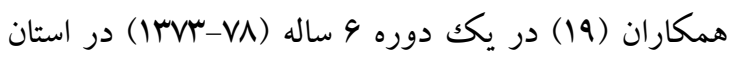

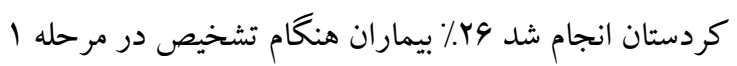

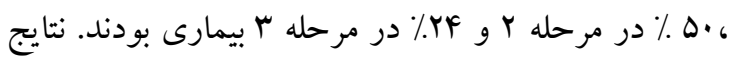

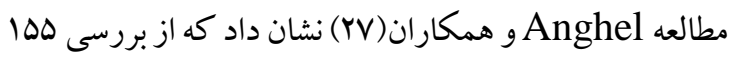
بيمار مبتلا به سرطان مثانه، از نظر توزيع مرحله بيمارى، تعداد

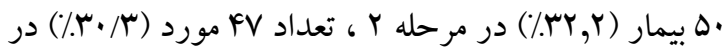
مرحله r و DV مورد (FV/F/\%) در مرحله F بيمارى بودند. تفاوت در تشخيص مرحله بيمارى مى تواند به دليل ابزارهاى

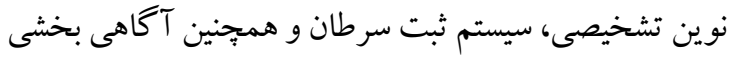
به جامعه نقش مهمى در تشخيص زودرس و انجام اقدامات

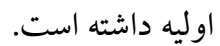
در مطالعه حاضر، روش درمانى براى \$4/ه/ بيماران TURBT بود و براى بr/٪ از بيماران TURBT و داخل مثانه انجام شد. نتايج مطالعه Anghel و ونكائ

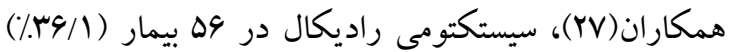

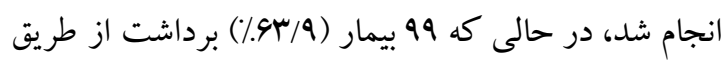

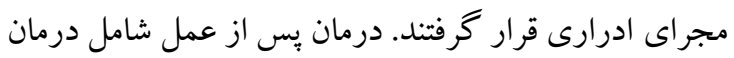

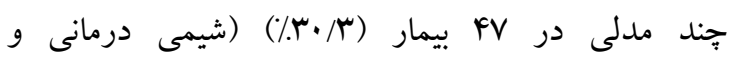

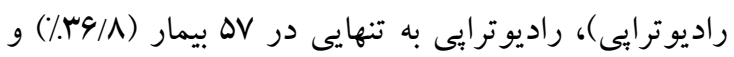

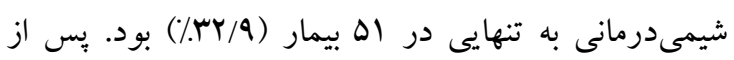

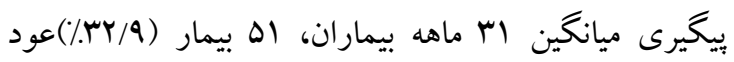

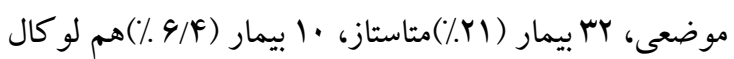

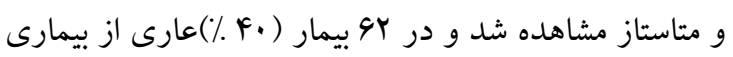
بودند. عليرغم رويكردهاى تركيبى درمانى، سرطان مثانه همجِنان يكك بيمارى تهاجمى است و ميزان عود آن بالا است.

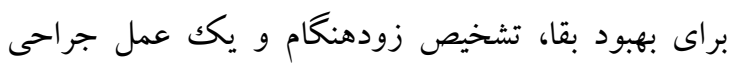
راديكال تهاجمى با هدف بهبودى (سيستكتومى) و درمان تر كيبى (راديو ترايى و شيمى درمانى) مورد نياز است.
سرطان مثانه شناخته شدهاند شامل مصرف سيگار و مواجهه شغلى با بعضى مواد شيميايى ازجمله آمين هاى آروماتيك متك

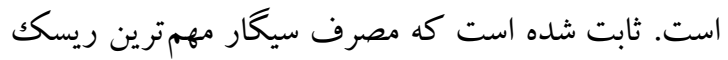

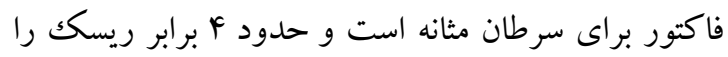

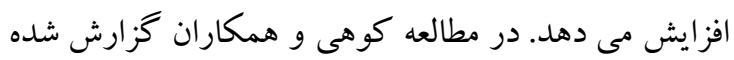

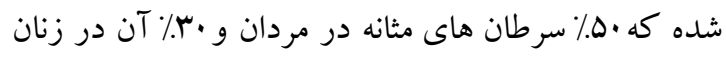

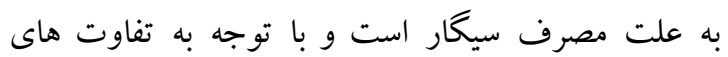
موجود در بروز سرطان مثانه در نواحى مختلف مى توان

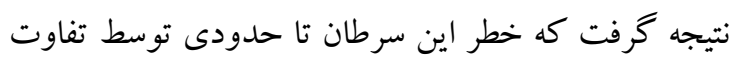
هاى نزادى و محيطى نيز مشخص مى شود (rT).

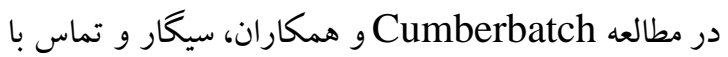
كارسينوزن هاى شغلى به عنوان شايع ترين ريسك فاكتورهاى محيطى سرطان مثانه شناخته شد(أ) و در مطالعه Pashos و همكاران سيگار به عنوان مهم ترين عامل محيطى بروز سرطان مثانه شناخته شد (9).

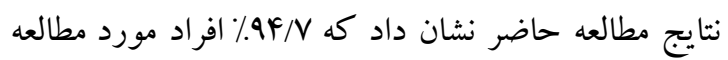
با بيشترين فراوانى نتيجه هيستوياتولوزى بيمارى از نوع نئان Transitional Cell Carcinoma فراوانى مربوط به آدنو كارسينوما و سرطان سلول سنگفرشى بود.در مطالعهاى كه در كشور جين جهت بررسى وضعيت

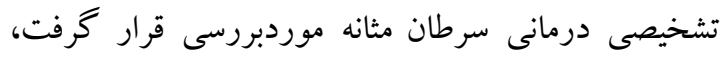

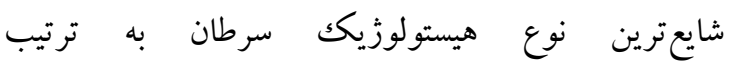
\% \%1/ศ با Transitional Cell Carcinoma آدنو كارسينوما با \/1\% و نوع سلول سنگفرشى 1/ 1\% بوده است(سا). در مطالعه شافى و همكاران كه 94\% بيماران

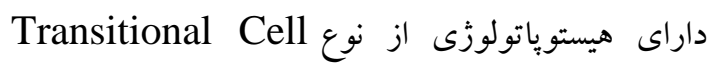
Carcinoma عضله داشتند (1)). در مطالعه صوفى مجيديور و همكاران

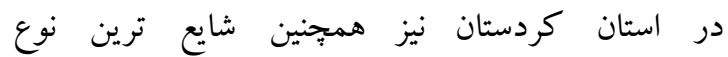

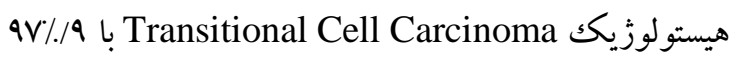
بود (19). 


$$
\begin{aligned}
& \text { مر احل اوليه قابل درمان است، جهت افزايش كيفيت زندگى } \\
& \text { بيماران و جلو گيرى از تحميل درمانهاى برهزينه بر سيستم }
\end{aligned}
$$

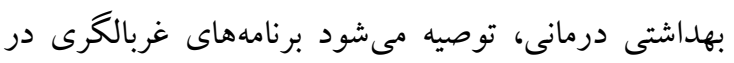

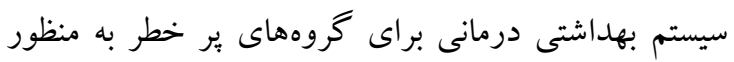

$$
\begin{aligned}
& \text { ارتقاى كيفيت زندگى و بقاى بيماران تدوين شود. }
\end{aligned}
$$

$$
\text { تشكر و قدردانى }
$$

اين مطالعه، نتيجه بايايان نامه دانشجويى بز شكى بود كه در

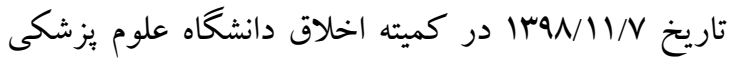
كردستان با كد (IR.MUK.REC.1398.272) به تصويب رسيد. از معاونت محترم تحقيقات و فن آورى دانشكاه علوم يز شكى كردستان و دانشكده يز شكى به عنوان حمايت كننده مالى و همجنين كميته تحقيقات دانشجويى، كار كنان محترم معاونت بهداشتى استان كردستان و واحد توسعه تحقيقات بالينى بيمارستان كوثر سنندج كه ما را در انجام اين تحقيق يارى نمودند تقدير و تشكر به عمل مى آيد.
نتيجه كيرى نتايج مطالعه حاضر نشان مىدهد كه تعداد افراد مبتلا به

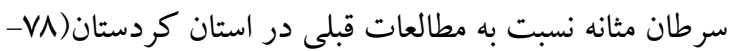

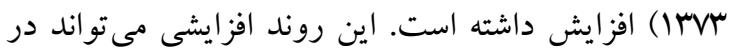
زمينه افزايش جمعيت استان، افزايش جمعيت شهرنشين و مهاجرت از روستا به شهر، بيشرفت روشهاى تشخيصى

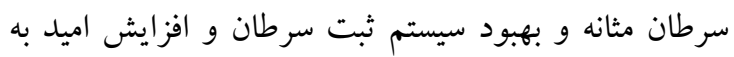
زندگى باشد. با توجه به نتايج مطالعه حاضر، فراوانى سرطان

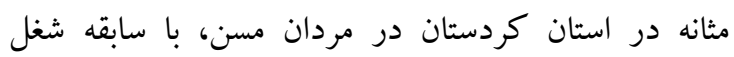
كشاورزى، افراد ساكن شهر و افراد با سابقه مصرف سيخار بيشتر است. از اين رو به نظر مىرسد با توجه به بروز بيشتر اين سرطان در جنس مذكر و همجنين شناخته شده بودن مهم ترين

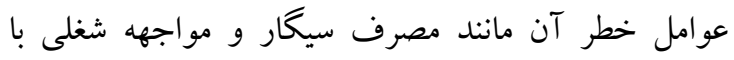

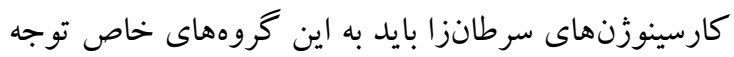

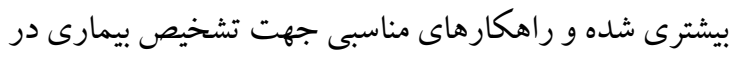

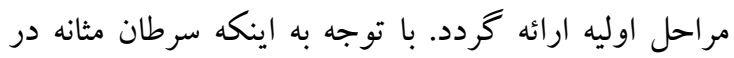

1.Bott S, Patel U, Djavan B, Caroll PR, editors. Images in Urology: Diagnosis and Management. Springer Sci. Rev. 2012 Jan 5.

2.Creel P. Bladder Cancer: Epidemiology, Diagnosis, and Treatment. Semin. Oncol. Nurs. 2007;23:S3-S10.

3.Whelan P. Survival from bladder cancer in England and Wales up to 2001. Br. J. Cancer. 2008;99(1):S90-S2.

4.Andrew AS, Gui J, Sanderson AC, Mason RA, Morlock EV, Schned AR, et al. Bladder cancer SNP panel predicts susceptibility and survival. Hum. Genet. 2009;125(5-6):527-39.

5.Vedder MM, Márquez M, de Bekker-Grob EW, Calle ML, Dyrskjøt L, Kogevinas M, et al. Risk Prediction Scores for Recurrence and Progression of Non-Muscle Invasive Bladder Cancer: An International Validation in Primary Tumours. PloS one. 2014; 9(6):e96849.

6.Wu S, Li F, Huang X, Hua Q, Huang T, Liu Z, et al. The association of tea consumption with bladder cancer risk: a meta-analysis. Asia Pac. J. Clin. Nutr. 2013;22(1):128-37

7.Jemal A, Bray F, Center MM, Ferlay J, Ward E, Forman D. Global cancer statistics. CA Cancer J Clin. 2011; 61(2):69-90.

8.Lynch CF, Cohen MB. Urinary system. Cancer 1995; 75(Suppl 1): 316-29.

9.Feldman AR, Kessler L, Myers MH, Naughton MD. The prevalence of cancer. N Engl J Med. 1986 Nov 27;315(22):1394-7.

10.Burger M, Catto JW, Dalbagni G, Grossman HB, Herr H, Karakiewicz P, Kassouf W, Kiemeney LA, La Vecchia C, S hariat S, Lotan Y. Epidemiology and risk factors of urothelial bladder cancer. Eur. Urol. 2013 Feb 1;63(2):234-41.

11.BosettiC, BertuccioP,Chatenoud N, NegriE,Vecchia L, Levi F. Trends in mortality from urologic cancers in Europe, 1970- 2008. Eur. Urol. 2011; 60(1): 1-15. 
12.Nieh PT, Marshall FF. Surgery of bladder cancer. Campbell-Walsh urology. 9th ed. Philadelphia: Saunders. 2007:2503-5.

13.Pashos CL, Botteman MF, Laskin BL, Redaelli A. Bladder cancer: epidemiology, diagnosis, and management. Cancer Pract. 2002 Nov;10(6):311-22.

14.Li K, Lin T, Xue W, Mu X, Xu E, Yang X, Chen F, Li G, Ma L, Wang G, Liang C. Current status of diagnosis and treatment of bladder cancer in china-analyses of chinese bladder cancer consortium database. Asian J Urol. 2015 Apr 1;2(2):63-9.

15.Cumberbatch MG, Jubber I, Black PC, Esperto F, Figueroa JD, Kamat AM, Kiemeney L, Lotan Y, Pang K, Silverman DT, Znaor A. Epidemiology of bladder cancer: a systematic review and contemporary update of risk factors in 2018. Eur Urol. 2018 Dec 1;74(6):784-95.

16.Cheng L, Neumann RM, Weaver AL, Spotts BE, Bostwick DG. Predicting cancer progression in patients with stage T1 bladder carcinoma. J Clin Oncol. 1999 Oct;17(10):3182-7.

17.Schultzel M, Saltzstein SL, Downs TM,Shimasaki S, Sanders C, Sadler GR. Late age (85 years or older) peak incidence of bladder cancer. J Urol. 2008; 179(4):1302-5; discussion 1305-6.

18.Yeole B, Jussawalla D. Descriptive epidemiological assessment of urinary bladder\& kidney cancers in Greater Bombay. Indian J. Med. Res. 1997; 106:517-23.

19.Shafi H, Ali Ramaji A, Akbarzadeh Pasha A, Yousefnia Pasha Y, Kasayan A, .Aghajanimir M, et al. A Survey on 175 Cases of Bladder Cancer in the Patients Who Referred to the Hospitals Affiliated to Babol University of Medical Sciences, Iran (2001-2011). J. Babol Univ. Med. Sci. 2013; 15 (2) :116-122

20.SoufiMajidpour HA, Rahimi EA, Malekpour M.H. The Incidence Rate of Bladder Cancer andDemographic Characteristics of the Patients in Kurdistan Province from Year 1994 To 1999. Sci. J. Kurd. Univ. Med. Sci. 2001; 5(2):22-6.

21.Farahmand, Almasi-Hashiani A. Epidemiology of Bladder Cancers in Fars Province, Southern Iran (2003-2008). J. Kerman Univ. Medical Sci. 2013; 20(4):387-94.

22.Akbarzadeh pasha A, mohammadikenari H,Alizadehnavaei R, Hajian K. The Incidence of Bladder Cancer in Mazandaran Province for Three Years. J. Babol Univ. Med. Sci. 2012; 14(3):804

23.Rafiemanesh H, Lotfi Z, Bakhtazad S, Ghoncheh M, Salehiniya H. The epidemiological and histological trend of bladder cancer in Iran. J Cancer Res Ther. 2018; 14(3):532-6.

24.Koohi F, Salehiniya H. The trend of incidence of bladder cancer in Iran, 2003-2009. Med J Urm Univ Med Sci. 2015; 26 (1) :1-9

25.Ploeg M, Aben KK, Kiemeney LA. The present and future burden of urinary bladder cancer in the world. World J. Urol. 2009;27(3):289-93.

26.Madeb R, Messing EM. Gender, racial and age differences in bladder cancer incidence and mortality. Urologic Oncology 2004;22(2):86-92.

27.EjazA,Ghasemkhani O, Dastoori $\mathrm{P}$.Recurrence rate and prognostic factors of superficial bladder cancer in Shiraz ShahidFaghihi Hospital during the years 1998-2001. J. Adv. Med. Biomed. Res. 2003;11(42):1-9

28.Anghel RM, Gales LN, Trifanescu OG. Outcome of urinary bladder cancer after combined therapies. J. med. life. 2016 Apr;9(2):153. 